\title{
Mitral regurgitation detected during the intraoperative period after atrial septal defect closure: a case report
}

\author{
Joo Hyun Jun', Min-Kyung Kang², Joon-Sang Hyeon', Eunha Choi', Youngrok Kim', Ki Seok Kim³, \\ Mi Hwa Chung ${ }^{1}$ and In-Jung Jun ${ }^{1 *}$ (it)
}

\begin{abstract}
Background: Atrial septal defect (ASD) is a congenital cardiac defect often diagnosed in adult patients. Mitral regurgitation (MR) observed in ASD patients mostly improves after ASD closure. However, a subset of adult ASD patients present new-onset MR or aggravation of preexisting MR after ASD closure. Intraoperative MR aggravation after surgical ASD closure is a rare occurrence which has not been reported in the literature to date.

Case presentation: A 54-year-old woman was referred to our center due to large secundum ASD with a diameter of $17 \mathrm{~mm}$ which was incidentally detected on pre-operative echocardiography at a local clinic. Surgical repair of ASD under mini-thoracotomy was performed. After completion of the operation, intra-operative transesophageal echocardiography showed newly developed Grade II MR which subsequently deteriorated to severe level on postoperative day 3. Because the patient was asymptomatic, we decided to observe closely and treat conservatively with diuretics. Thereafter, echocardiography was evaluated on postoperative day 10 and MR disappeared to trivial level.

Conclusions: Intraoperative MR aggravation is a rare complication following ASD closure. The possibility of MR aggravation should be evaluated in all ASD patients prior to surgery. This case highlights the importance of mitral leaflet examination after ASD closure for early detection of MR.
\end{abstract}

Keywords: Mitral regurgitation, Atrial septal defect, Echocardiography

\section{Background}

Atrial septal defect (ASD) is a congenital cardiac defect often diagnosed in adult patients [1]. Mild mitral regurgitation (MR) associated with ASD is often improved after shunt closure which reduces right ventricular volume overload and restores ventricular septal configuration [2]. However, a subset of adult ASD patients with coexisting structural changes in the heart chambers present new-onset MR or aggravation of preexisting MR after ASD closure [3]. There are several reports of postoperative MR aggravation after ASD closure [3-5], but to the best of our knowledge, intraoperative detection of increased MR has not been reported previously. Here,

\footnotetext{
* Correspondence: christine17@hanmail.net

${ }^{1}$ Department of Anesthesiology and Pain Medicine, Kangnam Sacred Heart Hospital, Hallym University College of Medicine, 948-1, Daerim 1-dong, Yeongdeungpo-gu, Seoul 150-950, South Korea

Full list of author information is available at the end of the article
}

we evaluate a rare case of MR aggravation which was detected during the intraoperative period directly after ASD closure.

\section{Case presentation}

A 54-year-old woman was referred to our center due to right ventricular enlargement which was incidentally detected on pre-operative echocardiography for ankle surgery at a local clinic. The patient was asymptomatic and in normal sinus rhythm. A transthoracic echocardiography (TTE) showed a large secundum ASD with a diameter of $17 \mathrm{~mm}$. A transesophageal echocardiography (TEE) was performed and showed $20 \times 23 \mathrm{~mm}$ secundum ASD with left to right shunt and right ventricle (RV), right atrium (RA) enlargement (Fig. 1a). The patient had a D-shaped small left ventricle (LV) with a left ventricular ejection fraction of 59\%. Mitral valve leaflets 


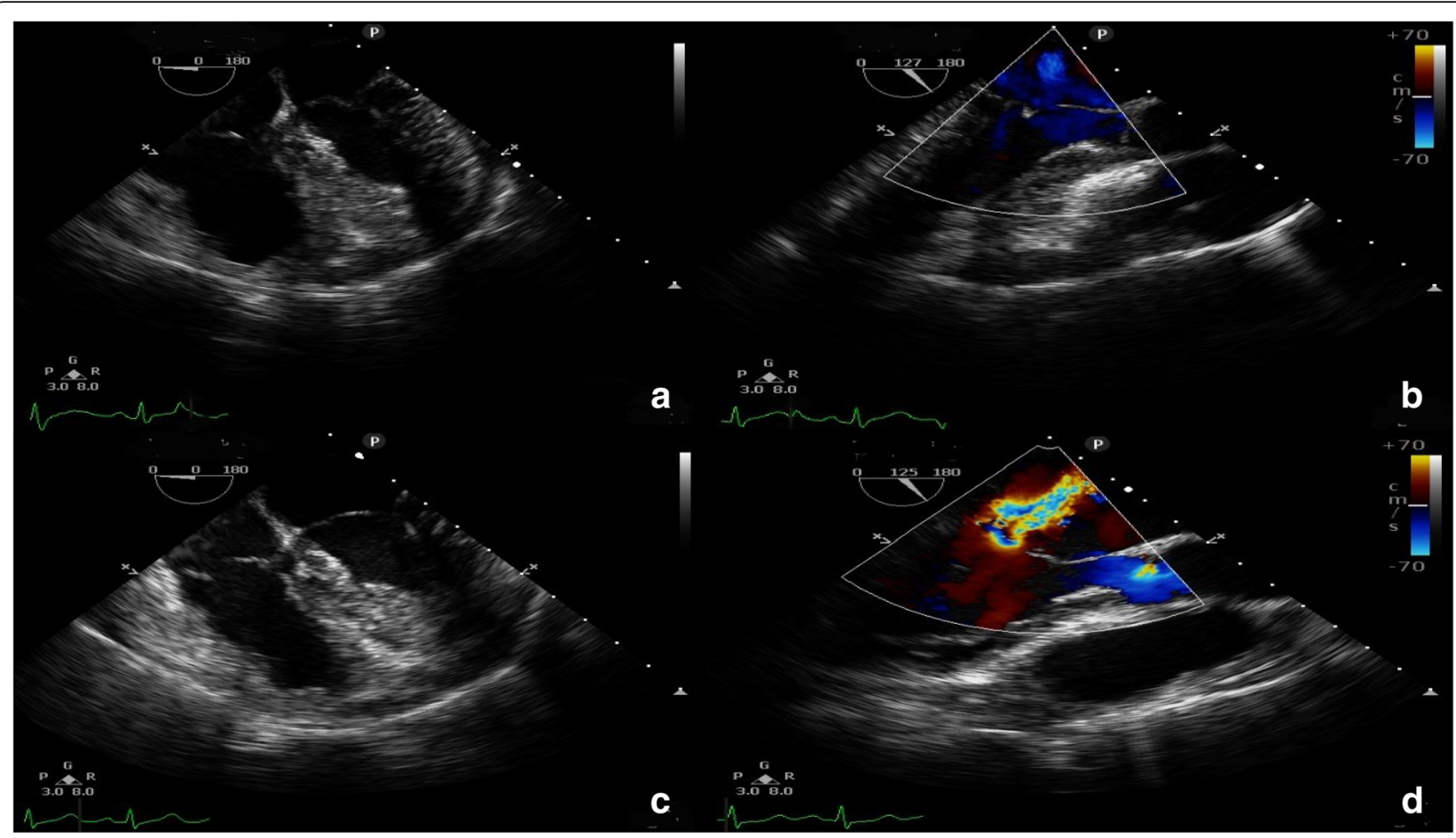

Fig. 1 Transesophageal echocardiography was evaluated before $(\mathbf{a}, \mathbf{b})$ and after $(\mathbf{c}, \mathbf{d})$ ASD closure. (a) Preoperative D-shaped small left ventricle with dilated right ventricle. (b) No mitral regurgitation noted. (c) Postoperative rightward deviated ventricular septum with dilated mitral valve annulus. (d) Newly developed mitral regurgitation after atrial septal defect closure

were normal with no MR detected (Fig. 1b). Moderate tricuspid regurgitation (Grade II) due to dilated tricuspid valve annulus $(46 \mathrm{~mm})$ and mild pulmonary hypertension were observed. The rims to both sides of the superior vena cava and inferior vena cava were short, thus surgical repair of ASD under mini-thoracotomy was planned.

In the operating room, standard vital signs (pulse oximetry, end-tidal carbon dioxide, electrocardiogram, and non-invasive blood pressure) were monitored. The left radial artery was catheterized for continuous arterial blood pressure monitoring. After 3 min of 100\% pre-oxygenation, general anesthesia was induced with midazolam ( $3 \mathrm{mg}$ ) followed by continuous infusion of propofol with remifentanil, and bolus administration of rocuronium $(50 \mathrm{mg})$. The patient was intubated with a $35 \mathrm{Fr}$ left-sided double-lumen tube for one-lung ventilation. A central venous catheter was inserted via the right subclavian vein because the right internal jugular vein was reserved for superior vena cava cannulation for cardiopulmonary bypass (CPB). A TEE probe was inserted to permit close observation.

Right anterolateral mini-thoracotomy was done via 4th Intercostal space. Following full anticoagulation with heparin given at a dose of $300 \mathrm{IU} / \mathrm{kg}, \mathrm{CPB}$ was instituted using femoral artery, femoral vein and right internal jugular vein cannulation. Next, the aortic Detachable
Glauber clamp (Cardiomedical GmbH, Germany) was deployed for aortic cross-clamp, and $2000 \mathrm{~mL}$ of Custodiol $^{\circ}$ HTK (Koehler Chemie, Bensheim, Germany) solution was infused through aortic root cannula for myocardial protection. Moderate Hypothermia of $31.5^{\circ} \mathrm{C}$ was permitted as measured by nasopharyngeal and rectal probes. Subsequently, right atrium was opened and ASD was closed with a trimmed bovine pericardial patch. Tricuspid ring annuloplasty and right atrium reduction plasty were also conducted. After completion of the operation, right atrium was closed and $\mathrm{CPB}$ was weaned.

Intra-operative TEE showed that ASD was closed with no remnant inter-atrial shunt. There was no tricuspid regurgitation and left ventricular ejection fraction was 55\%. Newly developed Grade II MR with end-diastolic rightward deviated inter-ventricular septum was detected which was not found in pre-operative echocardiography (Fig. 1c, d). We notified the surgeon of the newly developed MR. Because no abnormal findings, such as mitral valve prolapse, perforation, or chordae rupture, were observed in the mitral valve leaflets, it was determined that the surgery should proceed. No further adverse surgical events occurred throughout the remainder of the surgical procedure. The surgery lasted for $345 \mathrm{~min}$ with the CPB time of $190 \mathrm{~min}$ and aortic cross-clamp time of $140 \mathrm{~min}$. The estimated blood loss of $800 \mathrm{ml}$. After 
surgery, the patient was transferred to the Intensive Care Unit. Bilateral lung haziness due to acute MR was observed in the immediate post-operative chest $\mathrm{x}$-ray. Otherwise, the vital signs were stable without complaint of any symptoms. The patient was extubated after $3 \mathrm{~h}$ on arrival of the intensive care unit and transferred to general ward on postoperative day (POD) 1.

Transesophageal echocardiography on POD 3 confirmed that the ASD patch was intact without shunt flow or remnant tricuspid regurgitation. Both left and right ventricular function was well preserved with left ventricular ejection fraction of $69 \%$. However, LV diastolic dysfunction $\left(E / E^{\prime}=26\right)$ and aggravated pulmonary hypertension which was not observed in the preoperative TEE was found. The MR was shown to have deteriorated to severe level without evidence of vegetation or chordae rupture (Fig. 2). Because the patient was asymptomatic, conservative treatment using diuretics and close monitoring was determined to be the best course of action. Daily follow-up chest x-ray showed gradual improvement in pulmonary edema. On POD 6, the patient was discharged and attend follow-up outpatient appointments. On POD 10, TTE was evaluated. MR disappeared to trivial level and the LV chamber size and deviated septum became normalized (Fig. 3).

\section{Discussion and conclusions}

Mitral regurgitation is observed in less than $10 \%$ of adult ASD patients caused by mitral valve prolapse related to longstanding structural changes of the LV secondary to RV volume overload [1]. Generally, ASD closure improves MR by reducing the RV volume [4]. However, deterioration of mitral valve competence is reported in around $10 \%$ of patients undergoing ASD closure [3-5].

Previous studies have suggested several mechanisms of aggravation of MR [3, 4]. Intrinsic MV abnormality and subsequent poor coaptation of MV may have been masked by the abnormal septal configuration in ASD patients [6]. Also, perioperative atrial fibrillation is related to aggravation of MR [1]. Atrial fibrillation frequently causes left atrium (LA) enlargement and atrial fibrillation patients with normal LA size often have impaired LA function $[7,8]$. With LA enlargement or LA impairment, LA posterior wall extends beyond LV and results in poor coaptation of mitral valve $[1,9]$.

Our patient had no mitral lesion and presented normal electrocardiography. Thus, the mechanism of increased MR of the present case is assumed as longstanding adaptation of MV annulus geometry to the abnormal septal configuration and failure of adaptation to the cardiac geometric changes after ASD closure [10]. ASD shunt closure increases left ventricular volume and leftward deviated interventricular septum becomes normal [11]. Although mitral configuration normalizes in most of the patients, failure of mitral competence to acutely improved LV geometry after ASD closure may cause worsening of MR [10]. In a subset of adult ASD patients with underlying age-dependent decline of LV compliance,

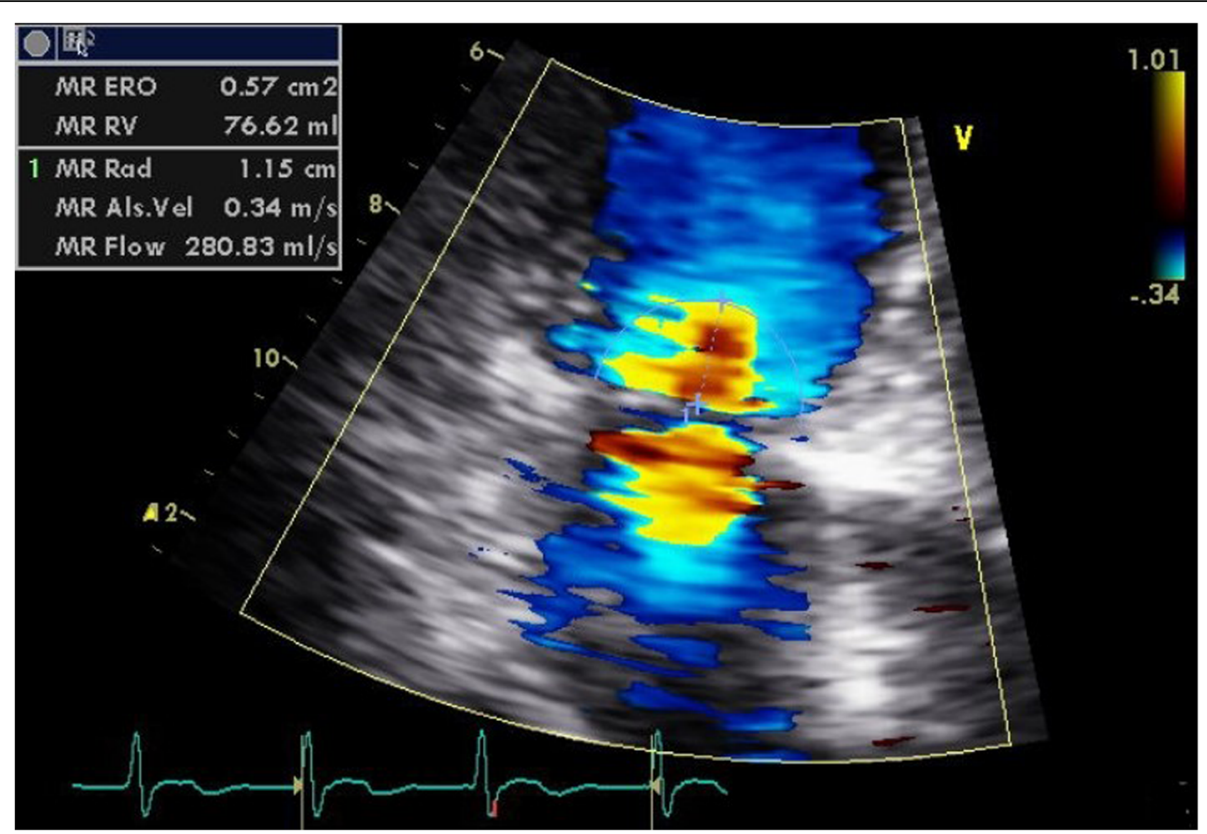

Fig. 2 Transthoracic echocardiography showed that mitral regurgitation was deteriorated to a severe level on postoperative day 3 (Effective regurgitation orifice area $0.57 \mathrm{~cm}^{2}$ ) 


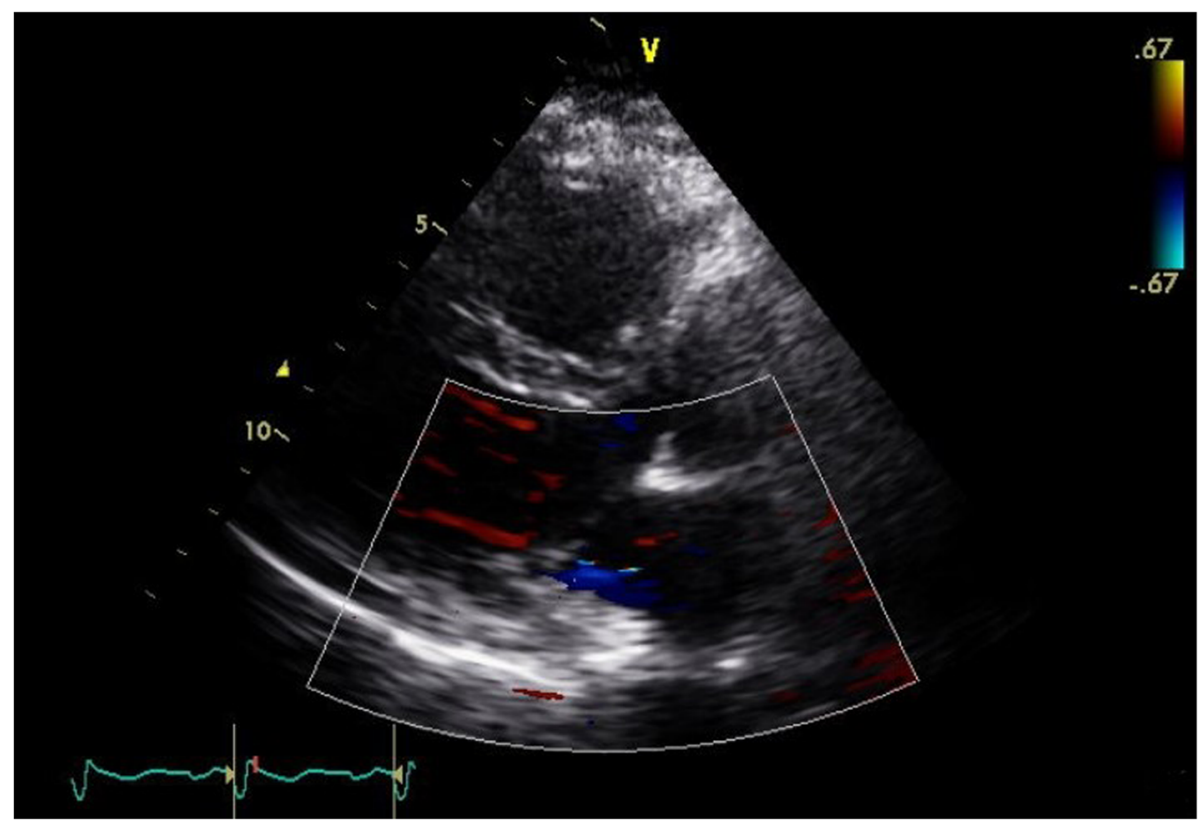

Fig. 3 On postoperative day 10, transthoracic echocardiography showed that mitral regurgitation disappeared

the possibility of failure of mitral competence to acutely improved LV geometry becomes higher $[2,12]$.

Preoperative echocardiographic features are useful in predicting postoperative MR. Risk factors for MR include D-shaped LV, large ASD, small LV and RV horizontal diameter to vertical diameter ratio, abnormal shape of mitral leaflets $[1,2,4]$. Also, larger pulmonary to systemic flow ratio $(\mathrm{Qp} / \mathrm{Qs})$ and high peak tricuspid regurgitation velocity have been identified as risk factors for MR [13]. As our patient had preoperative echocardiographic features of D-shaped LV, large ASD, and small LV horizontal diameter to vertical diameter ratio, the risk of postoperative MR after ASD was high.

The present case is unique in that MR aggravation was detected during the intraoperative period directly after ASD closure and the MV apparatus quickly adapted LV geometry by POD 10 . We believe that intraoperative MR aggravation after surgical ASD closure is a rare occurrence which, to the best of our knowledge, has not been reported in the literature to date. Cardiac remodeling usually begins immediately after ASD closure and continues to steadily improve over subsequent months [14, 15]. MR worsening is generally detected within 5 years in $50-62.5 \%$ of patients and the rest in more than 5 years after ASD closure [1]. Surgical closure, compared to catheter closure, may have detrimental effect on diastolic function in the early postoperative period from use of CPB which may result in MR worsening [14]. We excluded myocardial stunning as a factor of postoperative mitral regurgitation aggravation because both left and right ventricular function was well preserved without need of inotropic support. We assumed that acute LV volume loading after ASD shunt closure in the preexisting D-shaped small LV configuration influenced the development of severe MR. Moreover, acute diastolic dysfunction appear to have contributed in MR aggravation by increasing LV filling pressure [16]. Acute compensation may have been possible because the patient did not have left sided heart failure and mitral leaflets were normal. Thus, LV compliance improved promptly inducing normalization of cardiac chambers with postoperative supportive care only.

For patients at high-risk of MR deterioration, prophylactic mitral valve annuloplasty may be considered [4]. We decided to observe closely and treat conservatively with diuretics instead of conducting mitral annuloplasty. We reached the decision because mitral leaflets were normal and we believed that reopening the heart chamber after the minithoracotomy placed an unnecessary burden on the patient. Mitral leaflet examination through intraoperative echocardiography is crucial for early detection of MR. The American College of Cardiology/American Heart Association guidelines for the management of adults with congenital heart disease recommend clinical and transesophageal echocardiographic follow-up after ASD closure at $24 \mathrm{~h}, 1$ month, 6 months, and 1 year and at regular intervals there after [17]. If severe symptomatic MR develops with mitral leaflet motion abnormality, surgery may be advised. 


\section{Abbreviations}

ASD: atrial septal defect; CPB: cardiopulmonary bypass; LA: left atrium; LV: left ventricle; MR: mitral regurgitation; POD: postoperative day; RA: right atrium; RV: right ventricle; TEE: transesophageal echocardiography; TTE: transthoracic echocardiography

\section{Acknowledgements}

Not applicable.

\section{Available data and materials}

Not applicable.

\section{Authors' contributions}

IJJ wrote the manuscript. JJ, MKK participated in manuscript drafting, discussion of the case and revision of the manuscript. JSH participated in manuscript drafting. EC, YK, KSK, MHC contributed in revision of the manuscript. All authors read and approved the final manuscript.

\section{Funding}

None.

Ethics approval and consent to participate

Not applicable.

\section{Consent for publication}

Written informed consent for publication of the clinical details was obtained from the patient. A copy of the consent is available for review on request.

\section{Competing interests}

The authors declare that they have no competing interests.

\section{Author details}

'Department of Anesthesiology and Pain Medicine, Kangnam Sacred Heart Hospital, Hallym University College of Medicine, 948-1, Daerim 1-dong, Yeongdeungpo-gu, Seoul 150-950, South Korea. ${ }^{2}$ Department of Cardiology, Kangnam Sacred Heart Hospital, Hallym University Medical Center, Seoul, South Korea. ${ }^{3}$ Department of Anesthesiology and Pain Medicine, Fine Pain Clinic, Seochogu, Seoul, South Korea.

Received: 22 May 2019 Accepted: 15 July 2019

Published online: 22 July 2019

\section{References}

1. Nishimura S, Izumi C, Amano M, Miyake M, Tamura T, Kondo H, et al. Incidence and predictors of aggravation of mitral regurgitation after atrial septal defect closure. Ann Thorac Surg. 2017;104(1):205-10.

2. Hiraishi M, Tanaka H, Motoji Y, Sawa T, Tsuji T, Miyoshi T, et al. Impact of right ventricular geometry on mitral regurgitation after Transcatheter closure of atrial septal defect. Int Heart J. 2015;56(5):516-21.

3. Nishiga M, Izumi C, Matsutani H, Hashiwada S, Takahashi S, Hayama Y, et al. A case of significantly increased mitral regurgitation early after atrial septal defect closure. J Echocardiogr. 2012;10(2):69-71.

4. Park JJ, Lee SC, Kim JB, Seo DJ, Song JM, Yun SC, et al. Deterioration of mitral valve competence after the repair of atrial septal defect in adults. Ann Thorac Surg. 2011;92(5):1629-33.

5. Wilson NJ, Smith J, Prommete B, O'Donnell C, Gentles TL, Ruygrok PN. Transcatheter closure of secundum atrial septal defects with the Amplatzer septal occluder in adults and children-follow-up closure rates, degree of mitral regurgitation and evolution of arrhythmias. Heart Lung Circ. 2008; 17(4):318-24.

6. Nakagawa K, Akagi T, Taniguchi M, Kijima Y, Goto K, Kusano KF, et al. Transcatheter closure of atrial septal defect in a geriatric population. Catheter Cardiovasc Interv. 2012;80(1):84-90.

7. Gupta DK, Shah AM, Giugliano RP, Ruff CT, Antman EM, Grip LT, et al. Left atrial structure and function in atrial fibrillation: ENGAGE AF-TIMl 48. Eur Heart J. 2014;35(22):1457-65.

8. Weyman A, Sanfilippo A, Hughes R. Atrial enlargement as a consequence of atrial fibrillation. Circulation. 1990;82:792-5.

9. Silbiger JJ. Novel pathogenetic mechanisms and structural adaptations in ischemic mitral regurgitation. J Am Soc Echocardiogr. 2013;26(10):1107-17.
10. Takaya Y, Kijima Y, Akagi T, Nakagawa K, Oe H, Taniguchi M, et al. Fate of mitral regurgitation after Transcatheter closure of atrial septal defect in adults. Am J Cardiol. 2015;116(3):458-62.

11. Pascotto M, Santoro G, Cerrato F, Caputo S, Bigazzi MC, lacono C, et al. Time-course of cardiac remodeling following transcatheter closure of atrial septal defect. Int J Cardiol. 2006;112(3):348-52.

12. Nagata S, Nimura Y, Sakakibara H, Beppu S, Park YD, Kawazoe K, et al. Mitral valve lesion associated with secundum atrial septal defect. Analysis by real time two dimensional echocardiography. Br Heart J. 1983;49(1):51-8.

13. Toyono M, Pettersson GB, Matsumura Y, Wada N, Fukuda S, Yamano T, et al. Preoperative and postoperative mitral valve prolapse and regurgitation in adult patients with secundum atrial septal defects. Echocardiography. 2008; 25(10):1086-93.

14. Thilen U, Persson S. Closure of atrial septal defect in the adult. Cardiac remodeling is an early event. Int J Cardiol. 2006:108(3):370-5.

15. Yoo BW, Kim JO, Eun LY, Choi JY, Kim DS. Time course of the changes in right and left ventricle function and associated factors after transcatheter closure of atrial septal defects. Congenit Heart Dis. 2018;13(1):131-9.

16. Ennezat PV, Marechaux S, Pibarot P, Le Jemtel TH. Secondary mitral regurgitation in heart failure with reduced or preserved left ventricular ejection fraction. Cardiology. 2013;125(2):110-7.

17. Jalal Z, Hascoet S, Baruteau AE, Iriart X, Kreitmann B, Boudjemline $Y$, et al. Long-term complications after Transcatheter atrial septal defect closure: a review of the medical literature. Can J Cardiol. 2016:32(11):1315 e11-8.

\section{Publisher's Note}

Springer Nature remains neutral with regard to jurisdictional claims in published maps and institutional affiliations.

\section{Ready to submit your research? Choose BMC and benefit from:}

- fast, convenient online submission

- thorough peer review by experienced researchers in your field

- rapid publication on acceptance

- support for research data, including large and complex data types

- gold Open Access which fosters wider collaboration and increased citations

- maximum visibility for your research: over $100 \mathrm{M}$ website views per year

At $\mathrm{BMC}$, research is always in progress.

Learn more biomedcentral.com/submissions 